\title{
TEENAGERS MENSTRUAL DYSFUNCTION IN RURAL AREAS IN FAYOUM AND ASSIUT GOVERNORATES
}

Abd Elsamie A. A., M.D.

Department of Obstetrics and Gynecology, Faculty of Medicine - El Fayoum

\section{ABSTRACT}

Objectives: To improve the level of services in adolescent Gynecology clinics for early management of gynecological risk factors in teenagers that may lead to subsequent maternal morbidity and or mortality.

Material and Methods: The study included 750 girsl (teenagers), selected from the outpatient clinics of the hospital. A complete medical examination was done and selected investigations were performed ranging from complete blood picture up to hormonal assays and ultrasound according to th patients complaint.

Results : The mean age of menarche was $12.7 \pm 32$ years, and the mean age of marriage was $17.3 \pm 4.2$ years. The commonest gynecolgical complaint was dysmenorrhea $61.3 \%$, While the second most common problem was abnormal uterine bleeding [14.8\%]; $35.15 \%$ of these were due to DUB, $29.79 \%$ were due to pelvic infections, and $28.83 \%$ were due to pregnancy complications (Abortion, APH).

Conclusion: teenagers with gynecological problems need special care in their management in a sensitive and gentle way. The majority of their problems can be dealt with in a simple way. The ability to differentiate normal from abnormal menstruation is an essential skill for practitioners who care for teenagers.

\section{INTRODUCTION}

Menarche, the onset of the first menstrual bleeding episode is a milestone of sexual maturation and is viewed as a significant rite of passage in many cultures. Parents and primary clinicians may not be aware of normal parameters for cycle length, amount and duration of flow. Thus many girsl with cycles that fall within the normal range are brought in for medical assessment, while others do not seek help for significant abnormalities.

Although anovulatory cycles are common, there are parameters for early adolescent menstrual patterns based on standard deviation from the mean. Knowing these parameters will help the physician to differentiate normal patterns of bleeding from those that may indicate an underlying abnormality. Adolescents frequently seek medical advice for menstrual complaints such as irregularity, cramping or heavy bleeding. While there is some overlap in etiologies between adolescent and adult patients, certain menstrual complaints in teenagers may signify different etiologies to those commonly found in adults ${ }^{(1)}$.

\section{Puberty and menarche \\ During puberty, estrogen levels increase and the development of a positive feed-back mechanism in response to rising estrogen levels triggers the surge of luteinising and follicle stimulating hormones. The onset of menstrual flow follows an increasing} frequency of these hormonal pulsations.

The seminal report of pubertal development comes from Marshall and Tanner where the average age of menarche in this study was 13.47 years ${ }^{(2)}$. Subsequent studies in the US have shown a slightly younger age of both pubertal development and menarche. Recently, a large study of 17.077 rigls in the United States showed ethnic differences, with white girls having average ages of menarche at 10.5 years, and thelarches at 10.0 years. For black girls, development occurred slightly earlier, with average ages of menarche at 8.6 years ${ }^{(3)}$. 
Median first cycle length after menarche was 34 days with $38.3 \%$ having a cycle length longer than 40 days $^{(4)}$.

A girls first period is usually of a median duration of 2-7 days Knowing these parameters, it may be helpful to talk to girsl concerning what to expect of their first period. Girls who have been educated about menarche will experience less anxiety when it does occur (5)

\section{Menstrual disorders:}

Disturbances of menstruation, either actual or perceived, are the commonest presenting complaints in out-patient gynecological clinics. There are three main complaints: dysmenorrhea, irregualr menses and excessive menstrual blecidng.

It is important to remember that the onset of menstruation does not mean that ovulation has occurred. $45 \%$ of girsl do not have ovulatory menstrual cycles for 2 ycars after menarche. The first menses are usually anovulatory. This is important in relation to the problems of irregular and excessive bleeding.

When a teen has abnormal bleeding, pregnancy must be ruled out, even if she states that she has not been sexually active. ${ }^{(6)}$.

\section{Selection of diagnostic tests:}

Selecting a useful diagnostic test should change our ability to predict whether a patient has a disease of interest or not. In addition, it should also be safe, easy 10 use and aceptable to patients. Utilization of such tests will lead to more accurate diagnosis and aid the selection of suitable treatment options.

Initial investigations include using abdominal ultrasound, and magnetic resonance imaging. Hematology to diagnose coagulation disorders mainly vonWillebrand's disease and idiopathic thrombocytopenial.

In our practice, we treat lirst and then only proceed to these investigations if the treatment is unsuccessful, unless the history is suggestive of endometriosis ${ }^{(7)}$.

Endocrine investigations include thyroid function tests, and prolactin, FSH and LH assays; lastly, androgen assay is rarely required in the management of menstrual disorders in teenagers ${ }^{(8)}$. The main objectives of this work include the early management of gynecological risk problems in teenage girls that may lead to subsequent medical complications. This would also help to guard against them, and improve the level of care for adolescence in gynecological clinics in developed countries.

\section{PATIENTS \& METHODS}

This study include d 750 teenage girls selected from the outpatient clinic of Gynecology at Alazhar Assiut University Hospital and Abshaway Elmarkazi Hospital El Fayoum Governorate, from August 2001 to August 2004. A full history was taken including a detailed menstrual history, then complete physical examination was performed. Investigations were done including full blood picture, coagulation profile (prothrombin time, and concentration, bleeding time. coagulation time) and hormonal assays for serum FSH, LH, T3, T4, TSH, prolactin and testosterone when needed.

Ultrasound examination was done for patients with menstrual troubles including amenorrhea or menorrhagia or early pregnancy complications. A pregnancy test using strip tests for urinary deterction of $\beta$ sub unit of HCG for married patients presenting with abnormal uterine bleeding when pregnancy was suspected.

\section{RESULTS}

The mean age of menarche was $12.7 \pm 3.2$ years (Range 9-15) years, and the mean age of marriage was 17.3 \pm 4.2 years (Range 13-22). The incidence of dysmenorrhea was $66.1 \%$; $85.8 \%$ sufferred from spasmodic dysmenorrhea and $14.2 \%$ had congestive dysmenorrhea (Table I).

The incidence of abnormal uterine bleeding was $14.8 \%$, (85\% with menorrhagia, $18 \%$ with polymenorrhea and $16 \%$ with metrorrhagia; some patients had more than one type of abnormal uterine bleeding). (Table II).

Examination and investigation for abnormal uterine bleeding revealed that $35.1 \%$ were due to dysfunctional uterine bleeding, $29.72 \%$ were due to pelvic inflammatory disease, another $28.83 \%$ were due to pregnancy complications, $3.60 \%$ were due to uterine fibroids and $2.70 \%$ were due to coagulation 
disorders (Table III). Primary amenorrhea was detected in $3.86 \%$ among the study group.

Etiological study of the primary amenorrhen revealed that $37.9 \%$ were due to polycystic ovary syndrome, $20.7 \%$ due to hypothyroidism, $27.6 \%$ duc to hyperprolactinemia, and $13.8 \%$ due to imperforate hymen and Mullerian duct agenesis (No uterus). (Table IV).

From the previous results it can be noticed that the incidence of PCOS was $1.47 \%$, while Hypolhyroidism was $0.8 \%$, Hyperprolactinacmin was present in $1.7 \%$, and congenital anomalies was detecled in $0.6 \%$.

Table I : Incidence of dysmenorrhoea among the teenagers of the study [n $460=61.3 \%$ ].

\begin{tabular}{|l|c|c|}
\hline \multicolumn{1}{|c|}{ Type } & Number & Percentage \\
\hline Spasmodic & 395 & $85.8 \%$ \\
\hline Congestive & 65 & $14.2 \%$ \\
\hline
\end{tabular}

Table II : Incidence of abnormal uterine bleeding among the tecnagers of the study* [n $=111=14.8 \%$ ].

\begin{tabular}{|l|c|c|}
\hline \multicolumn{1}{|c|}{ Type } & Number & Percentage \\
\hline Menorrhagia & 85 & $11.3 \%$ \\
\hline Polymenorrhoea & 18 & $2.4 \%$ \\
\hline Metrorrhagia & 16 & $1.6 \%$ \\
\hline
\end{tabular}

* Some patients had more than one type of abnormal utcrine bleading

Table III : Etiology and incidences of abnormal uterine bleeding among the studied tecnagers [total No 111$]=14.8 \%$.

\begin{tabular}{|l|c|c|}
\hline \multicolumn{1}{|c|}{ Type } & Number & Percentage \\
\hline Dysfunctional uterine bleeding & 39 & $35.15 \%$ \\
\hline Pelvic inflammatory disease & 33 & $29.72 \%$ \\
\hline Pregnancy complications & 32 & $28.83 \%$ \\
\hline Uterine myoma & 4 & $3.60 \%$ \\
\hline Coagulation defects & 3 & $2.70 \%$ \\
\hline
\end{tabular}

* Some patients had more than one type of abnormal uterinc bleeding

Table IV : The incidence of primary amenorrhea among the teenagers of the study and its etiology [n $=29=3.86 \%$ ].

\begin{tabular}{|l|c|c|}
\hline \multicolumn{1}{|c|}{ Type } & Number & Percentage \\
\hline PCOS & 11 & $37.9 \%$ \\
\hline Thyroid Function Disorders & 6 & $20.7 \%$ \\
\hline Hyperprolactinaemia & 8 & $27.6 \%$ \\
\hline Congenilal anomalies & 4 & $13.8 \%$ \\
a] Cryptomenorthoea & 3 & \\
b] Mullerian agenesis & 1 & \\
\hline
\end{tabular}




\section{DISCUSSION}

The gynecological problems of teenagers can pose difficulties in management, not just from the physical nature of the problem, but from associated emotional and psychological factors. The girls are often shy and embarrassed to discuss the more personal aspect of their lives. Hence, they often do not know where to turn for help. Added to this is lac $\vdots$ of knowledge and understanding as to what is happening to their bodies at this time. This may lead to fear ${ }^{(9)}$.

How the medical profession deals with these girls is important. What teenagers expect from doctors when they attend the clinic is proper understanding, and personal friendliness.

Disturbances of menstruation, either actual or pereeived, are the commonest presenting complaint in adoleseent gynecology clinics (9).

In the present study, the incidence of dysmenorrhoca was $61.3 \%$ in tecnagers while in another study the in incidence was around $75 \%{ }^{(3)}$. A study of North American girls aged 12-17: years reported dysmenorrhoea in 59\% (10).

Our study showed that the incidence of abnormal uterine bleeding among teenagers was $14.8 \%$ with $85 \%$ of these cases presenting with menorrhagia and $35.15 \%$ of these were due to dysfunctional uterine bleeding (DUB). Moreover, 29.79\% of these cases were due to pelvic inflammatory diseases.

The present report showed that the incidence of primary amenorrhea among teenagers was $3.86 \%$ with $37.9 \%$ of these wre duc to polycystic ovary syndrome, $20.7 \%$ with thyroid functional disorders and $27.6 \%$ having hyperprolactinacmia. Lastly, $13.8 \%$ of these were due to imperforate hymen and Mullerian agenesis.

\section{CONCLUSION}

Teenagers with gynecological problems need special care in their management in a sensitive and gentle approach. The majority of their problems can be dealt with in a simple way. The ability to differentiate normal from abnormal menstruation is an essential skill for practitioners who care for teenagers. Adolescent gynecology remains an important area to which greater care and interest should be given particularly by rural university hospitals in specialized adolescent gynecology clinics, in order to protect and promote the health of our teenagers.

\section{REFERENCES}

1. Paula JA, Hillard, Jane Ellery Dopkins menstruation in teenagers. Gynaecology forum 2003; vol 8, Ni 2 , 7-9.

2. Marshall WA, Tanner J M. Variations in pattern of pubertal changes in girsl. Arch Dis Child 1969; 44: 291-303.

3. Herman - Giddens Me, slora EJ, Wasserman RC, el al. Secondary sexual characteristics and menses in young girls seen in office practice: a study from the pediatric research in office settings networks. Pediatrics 1997; 99: 505-512.

4. World health organization multicenter study on menstruation ovulation in adolescent girls. II longitudinal study of menstrual patterns in the early postmenarcheal period, world health organization task force on adolescent reproductive health. J adolescent health care 1986; 7: 236-244.

5. Frank D, Williams T. attitudes about menstruation among fifth, sixth, and seventh-grade pre and post-monarchal girls. J schools Nurs 1999; 15: 25-31.

6. Classens E A, Cowell C A. acute adolescent menorrhagia. Am J obstet Gynaecol. 1988; 87: 603-609.

7. Johnson J. Level of knowledge among adolescent girls regarding effective treatment for dysmenorrhoea. $\mathrm{J}$ adolescent health care 1988; 9:b 398-402.

8. Justin clark $T$. Best practice in the diagnosis of menstrual dysfunction. Gynaecolgy forum 2003 vol 8 No 2 12-23.

9. Turner O. M., Adolescent gynaecology. Progress in obstetrics d Gynaccology 1999 volume 12 N0 12 215-233. 